\title{
Research on the Application of Context Theory in Vocabulary Study*
}

\author{
Xiaohui Xu \\ The School of Foreign Languages, Qingdao University of Science and Technology, Qingdao, China

\begin{abstract}
Context theory is usually used in reading comprehension. Some scholars tried to put it into the study of word meaning. The relationship between the word meanings and context, the functions of context to word meaning also have been analyzed in the paper.
\end{abstract}

Index Terms - context, word meaning, linguistic context, non-linguistic context

\section{INTRODUCTION}

In studying English, most of the students are accustomed to the old methods of learning. Usually they grasp grammatical rules, and then remember a large vocabulary. Actually it is a large obstacle on their way of learning English. So here comes the question: how to memorize so many English words and how to use them correctly and appropriately in writing and speaking. This shows that the teaching of words is a fundamental part in language.

In English class, a vast amount of teaching time is consumed by explanation and definition. Students compile page upon word list that they rarely have chance to practice. So the traditional translation method in the vocabulary teaching and learning should be discouraged, because it will lead students to acquire a bad habit of automatically matching words, regardless of real situation. Furthermore, this mechanical absorbing of words can lead to students' bad habit of study.

With the development of reform of vocabulary teaching, many teachers have explored new approaches to classroom teaching to change the situation in which study isn't combined with practical application. Applying context theory can change effectively to improve teaching quality of English teaching.

\section{LITERATURE REVIEW}

\section{A. B. Malinowski's View}

The concept of context was initiated by B. Malinowski, a Polish professor of anthropology, while he did the field work in the primitive culture. Malinowski though that "a text written by these people into this language could not be understood by any foreigners or by people living outside this society even if translated into their own languages because each message brought much more meanings than those expressed through the words, meanings that could only be understood if accompanied by the situation". Thus, "Malinowski introduced the notion of context of situation, meaning by environment of the text". (Halliday, 1989, p.6)

On the other hand, the limitation of Malinowski's conception of context is clear that little attention has been paid to the significance of language in the understanding of utterances.

\section{B. J. R Firth's View}

J. R. Firth was one of those who took part in Malinowski's seminars at the University of London. He was also one of the founders of British Functionalism greatly influenced by Malinowski. He not only accepts Malinowski's concept of "context of Situation" but extends it to linguistics. Firth is the first scholar to analyze language from the perspective of context and make a framework for the study of context thereafter. He states that "the context of situation is not to be interpreted in concrete terms as a sort of audiovisual record of the surrounding 'props' but was, rather, an abstract representation of the environment in terms of certain general categories having relevance to a text" (Halliday, 1978, $p$. 109).

\section{M. A. K Halliday's View}

Halliday remarks, "Knowledge is transmitted in social contexts, through relationships, like those of parent and child, or teacher and pupil, or classmates, that are defined in the value systems and ideology of the culture. And the words that are exchanged in these contexts get their meanings from activities in which they are embedded, which again are social activities with social agencies and goals." (Halliday, 1989, p.17)

Later, he develops the theory of situation into "register", "a more generalized interpretation intended as a basis for deriving the features of the text from the features of the situation." (Halliday, 1964, p.87) He defines register as a

\footnotetext{
* This paper is the partial result of Shandong Provincial Education Department project in 2012 “The study of multi-modality discourse's integrated modalities from the perspective of ecology of communication" (No. J12WG23).
} 
variety of language according to the use. Language varies as its function varies; it differs in different situations.

Absorbing the ideas of both Malinowski and Firth, Halliday proposed his own opinion on the study of the context. He employed Firth's idea of context to establish the systemic-functional theory in which the categories and their relations could be explicit.

According to Halliday and Hasan (1985), context is no longer just an abstract concept concerning the environment in which language is used, but an abstract theoretical category in which language can be interpreted from the perspective of semiotics.

\section{J. Lyons' View}

J. Lyons, an English linguist, makes a great contribution to the study of context. He proposes that "context is a theoretical construct, in the postulation of which the linguist abstracts from the actual situation and establishes as contextual all the factors which, by virtue of their influence upon the participants in the language event, systematically determine the form, the appropriateness or the meaning of utterances.” (Lyons, 1977, p.572)

\section{E. Study of Chinese Scholars}

$\mathrm{Hu}$ zhuangling also probes into the concept of context. He divided context into three categories: Linguistic context: "the accompanying context within a text"; Situational context: "some factors outside the text, including the relationship of participants, their communicative intention and the environment where the utterance occur"; Cultural context: "the speech community in which the speaker lives, including the custom and social culture". (Hu Zhuanglin, 2002, p. 78)

Professor He Zhaoxiong defines context as "the environment in which the language is used, illustrating context as two kinds of knowledge: inner-linguistic knowledge and extra-linguistic knowledge" (He Zhaoxiong, 1989, p.22). Many professionals support the idea of inferring word meanings form context.

\section{WORD MEANING AND CONTEXT}

\section{A. Research Questions}

The research takes qualitative approach. It is intended to find answers to the following:

(1)What are word meaning and context and the relationship between them?

(2)What are the classifications of word meaning and context?

(3)How are context theories used in vocabulary teaching in China?

\section{B. Classification of Word Meaning}

When we talk about the meaning of a word, we tend to think of dictionaries immediately and assume that the meaning exists in such books. But Dai Weidong states that dictionaries are put together by authors according to the ordinary usage of words, so the meaning of words is eventually determined by users of words not by dictionaries (Dai Weidong, 1998, p.89). In addition, dictionaries often tend to be behind the times. Bilingual dictionaries are especially less satisfactory because they usually provide only a list of glosses and have no definitions.

Many scholars have been trying to divide word meanings into different categories. Linguist Geoffrey Leech (1981) listed seven types of meaning of words and sentences.

\section{Grammatical Meaning}

"Grammatical meaning refers to that part of meaning of a word that indicates grammatical concept or relationship such as part of speech of words (nouns, verbs, adjectives, adverbs), singular and plural meaning of nouns, tense meaning of verbs and their inflectional forms". Geoffrey Leech (1981, p.78)

\section{Lexical Meaning}

Unlike grammatical meaning, this meaning is identical in all the forms of the word. Let us take the variables of the word do (make, makes, making, and made) as an example. They have different grammatical meanings of person, tense and so on, but in each of these forms we find one and the same semantic component serving the process of movement.

Lexical meaning can be subdivided into conceptual meaning and associative meaning.

\subsection{Conceptual Meaning}

"Conceptual meaning (also known as denotative meaning) is the meaning given in the dictionary and forms the core of word meaning. Being constant and relatively stable, conceptual meaning forms the basis for communication as the same word generally has the same conceptual meaning to all the speakers in the same speech community". Geoffrey Leech (1981, p.82) Dictionaries generally focus on conceptual meaning of words. It is that aspect of lexical meaning that makes communication possible.

\subsection{Associative Meaning}

"Associative meaning is the secondary meaning attached to conceptual meaning. It differs from conceptual meaning in that it is open-ended and indeterminate, liable to be influenced by such factors as culture, experience, religion, geographical region, class background, education, etc. It is the total of the meanings a person thinks of when he hears or reads the word". According to Leech (1981, p.85), associative meaning includes four types "connotative, stylistic, affective, and collocative".

2.3 Stylistic Meaning 
What's more, many words have stylistic features, which make them suitable for different contexts. The features form the stylistic meanings of words. In some dictionaries, the stylistic features are clearly marked as "formal", "informal", "literary", "slang" and so on. For example, cop and policeman have the same conceptual meaning, but differ in their stylistic values.

Leech (1981) thinks that language application can be grouped as different levels in different situations, that is formal and literary, colloquial, familiar and slang. Different words may be employed in different styles, and this part of word meaning constitutes the stylistic meaning of a word.

2.4 Affective Meaning

Affective meaning denotes the expression of feelings and attitudes of the speaker or writer. It is concerned with the speaker or writer's attitude towards the person or thing in question.

For example, just as statesman and politician, slender and skinner, fat and overweight. Statesman is admirable, but politician is looked down upon. In fact, affective meaning differs from one to another, from one culture to another culture. For example, the word dog may have quite different affective meanings in different countries. In western countries it is associated with "loyalty", "men's best friends" which are all positive meanings, while in China, dog is only a useful animal. Sometimes it implies negative meanings.

2.5 Collocative meaning

"Collocative meaning consists of associations a word acquires on account of the meaning of words which tend to occur in its environment". (Leech, 1981, p.88). For example, the pair of synonyms beautiful and handsome offers good illustration. These two words share the conceptual meaning of "good-looking", but are distinguished by the extent of nouns they collocate with: beautiful girl or flowers, handsome boy or car.

\section{Experiential Meaning}

Besides grammatical meaning and lexical meaning, there is the very special interpretation that is brought to each word by both speaker or writer and reader because of each person's own particular, personal experiences and those experiences that are common to the culture of which he or she is a part (Robinett, 1980, p.113). Sometimes it is not enough to know the lexical meaning of a word in order to understand and be understood completely. Experiential meaning is beneficial to the understanding of the passage.

\section{Context}

Context is of great importance for the understanding of word meaning. Without context, there is no way to determine the very sense of the word that the speaker or writer intended to convey; whereas with context there is generally no danger of misinterpretation, for meaning lives in context and the context defines meaning. Therefore, we may use context in vocabulary teaching to help students improve their word power and reading comprehension as well.

\section{Linguistic Context}

Linguistic context refers to the linguistic setting in which a word occurs. To put it in details, "it refers to the words, clauses, sentences in which a word appears and it may also cover a paragraph, a whole chapter and even the entire book". (Leech, 1981, p.91). Linguistic context includes lexical and grammatical context.

For example, the polysemous word such as make. This word conveys a large number of meanings and only context will determine exactly which is meant.

(1) He made (earned) a lot of money.

(2) We made (arrived at) Beijing in two hours.

(3) We have made (covered) 60 miles since noon.

(4) She will make (become) a good doctor.

(5) I do not like milk. But she made (forced) me drink it.

In the above sentences, make has different meaning according to the linguistic context.

\section{Grammatical Context}

When it appears in different grammatical contexts, a polysemous word may have different meanings. Take the verb get for example. Its meaning varies in different syntactical structures:

get $+n$. , as in

I got a present today (meaning "receive")

get+adj., as in

The food is getting cold. (meaning "become")

get+n.+infinitive, as in

I will get him to see a doctor. (meaning "to cause to do something")

So different get has different meaning in varies grammatical context.

\section{Situational Context}

"Non-linguistic context refers to the extra-linguistic factors abstracted from the physical environment and cultural settings in which the utterance occurs. It embraces the people, time, place, mode of transmission and even the whole cultural background". (Leech, 1981, p.94)

Non-linguistic context includes situational context and cultural context, which is also known as cultural knowledge.

Situational context refers to "the actual speech situation in which a word (or an utterance, or a speech event) occurs. Situational context is understood to be the physical, relatively easily identifiable level related to such factors as whom 
the participants are, and what the relationship is between them: parent and child, friends, employer and employee, or strangers". (Zhang Yunfei, 1988, p.237)

Where the language happens is also relevant; talking in a church is different in many ways from talking in the home or a restaurant, talking in the theatre is not like talking in a church.

Thus, situational context clues are important in determining the meaning of a word. The analysis of situational context is necessary. In vocabulary teaching, if students want to fully understand a word in a text, they should also know some of the background knowledge.

\section{Cultural Context}

"Cultural context represents an abstract way of people's social activities. Culture consists of all the shared elements of human society. This includes not only such material things as cities, organizations and schools, but also non-material things as ideas, customs, family patterns, relationships and languages". (Leech, 1981, p.98)

\section{Function of Context to Word}

Generally speaking, the role of context to word is illustrated from the following there aspects.

\section{Eliminating Ambiguities}

The context often makes the meaning of a polysemous word so certain that we do not think of the fact that it has different senses. Was it not for the context, the readers will be confused.

But in daily life, polysemous words do not create any ambiguity or confusion, because the word reaches us already prepared by what precedes and by what surrounds it, interpreted by time and place, and determined by the speaker's relevant features such as personality, age, sex, education, occupation, etc. That is the "context" in real life.

\section{Conveying Emotional Implications}

Another example is nice, which is an appreciative word. For example, the word "good" in the sentence "He is a good man" Means kind because the object is a person. But if the modified object is changed into "orange", "good" changes its connotation into the meaning of "sweet", because nobody will like a sour orange. Thus, only the context can show whether a word should be taken as a purely objective expression, whether it conveys and shows emotions, or whether an appreciative word is used in an unfavorable way. Observing context carefully seems to be the best way to catch the word's exact meaning.

\section{Supplying Information of Omitted Part}

As a rhetoric method, omitting is widely used in English communication. Without the instruction of context, however, omitting would probably hinder reader's understanding instead of improving it. The sentence "A rose is rose" is almost meaningless for people when they first read it. Only by getting to know the context will people catch the real meaning of the strange sentence. Then, we know that omitting would not work well without the help of the context.

From the above description, we can see that context, both linguistic and non-linguistic, plays an important role on the determination of word meaning.

Rivers (1968, p.53) suggests "introducing vocabulary items in such a way as to allow the student to infer the meaning from the context. She feels students should be encouraged to make intelligent guesses about word meanings". So we suggest a number of different context clues that can help students to infer the meaning of an unfamiliar word.

\section{Contextual Clues and Applications}

\section{A. Contextual Clues}

\section{Definition}

The most obvious source of help is the context that acts like a dictionary and defines a word. The writer often defines the meaning of the word right in the sentence or gives enough explanation for the meaning to be clear. For example:

Desalination, or the removal of salt from seawater, is a method of providing fresh water for business, home, and agricultural use.

"The removal of salt from seawater" is the definition of "desalination". The word "desalination" may be unfamiliar to some of the readers, so the writer makes an explanation in the former sentence.

\section{Synonym}

Very often learners can find in the same passage a familiar word that relates to a subject in a manner similar to the way that the unfamiliar term does. For example:

Cellphones have become ubiquitous; you can use and hear them everywhere.

From the description of the events in the sentence we know that the words ubiquitous and everywhere are synonymous.

\section{Antonym}

Words with opposite meanings may be found in the same context. For example:

My sister thinks it is futile to study hard the night before an exam, but I find it quite useful.

We note that useful and futile are opposites, so when we see the next pair of words in a parallel construction, we can assume that futile means "useless".

\section{Summary}

A summary clue may sum up a situation or an idea with a word or a phrase. For example: 
Mr. Brown donates money to the church, the schools, he also volunteers many hours in the nursing home. He is indeed altruistic.

From this description of Mr. Brown's deeds, readers may conclude that altruistic means unselfish.

\section{Simile}

A simile is a figure of speech that compares things. For this discussion, the important point is that the comparison may clarify a word's meaning. The following contexts illustrate this.

The ancient mammoth in Inner Mongolia, like other elephants, is huge.

With the help of like, the meaning of mammoth can be easily guessed out to be a kind of elephant.

\section{Grouping}

The appearance of a word in a series assigns it at least a general classification. For example:

The wallpaper was so colorful that I can only remember seeing yellow, aqua, and black.

This context demonstrates an important point: Knowing what a word in general (for instance, knowing that aqua is a kind of color) may be sufficient for comprehension, it may make the comprehension fluently.

\section{Appositive}

An appositive is another direct source of help with meanings. For example:

Thermostat, an instrument to shut off the heat when the temperature reaches 25 degree centigrade, was set in our room.

With the explanation, readers may understand the word thermostat easily.

\section{Hyponymy}

If the reader wants to identify the relationship between an unfamiliar word and a familiar word, he may get the relation that a general concept is accompanied by a specific example.

The garden contained almost every type of flowers: lily, tulip, morning-glory and sun flower.

Lily, tulip, morning-glory and sun flowers are of the same category, which are called hyponyms, while flower is a general term which encompasses all of the listed items. So it is easy for the readers to know the words' meaning with the help of the relationship.

\section{B. Applications of Linguistic Context to Vocabulary Teaching}

\section{Applications of Linguistic Context to Vocabulary Teaching}

1). To draw the readers' attention to cue words and phrases. "Signals of connection, such as and, but, that is to say and in spite of, relate sentences or parts of sentences to each other". Generally, they specify, "the way in which what is to follow is systematically connected to what has gone before”. (Halliday and Hasan, 1976, p. 227)

For example:

A court stenographer, that is, a person has to be able to take down more than 250 words a minute, is greatly needed.

By introducing the function of signal words, the definition, the restatement and some related information, readers may work out the meaning of the unfamiliar word. In this way, readers become sensitive to these signals of context clues, and they became skillful in finding and using them to infer the word's meaning successfully.

2). Guiding questions is important to direct the readers into a deep search of context clues. With their limited experience, common sense and word knowledge in the target language and without the guidance of the teacher, readers may find it hard to identify context clues.

3). Do exercises that make inference of the meaning of unknown words in short contexts. In these exercises, students may be asked to explain how they infer the meaning of new words. Gradually, they may get the key point.

\section{Application of Non-linguistic Context}

1) Application of Situational Context

In the process of vocabulary teaching, teachers should emphasize the importance of situation. For example, "mum", "female parent", "mother" the words must be employed in suitable occasions, cannot be confused. Otherwise you make a big mistake. "Mum" is for children in their family and informal spoken word. "Mother" is neutral word. "Female parent" is a specialized term, and it can not be used in our daily life.

2) Application of Cultural Knowledge

To overcome the cultural failures, we English teachers should introduce some related cultural knowledge to students so that they can understand such words and phrases better and be informed to read more books concerning the life-styles and cultures of English-speaking countries.

The application of cultural knowledge to the teaching of vocabulary is helpful for students to understand word meaning. So in the teaching practice, teachers should encourage the students to enlarge their world knowledge, especially the knowledge about the western cultures, customs, historical events and habits, and take every chance to convey cultural knowledge to students in order to let them achieve better interpretation of English vocabulary.

\section{SUMMARY AND FURTHER RESEARCH}

According to the detail analysis, we get a conclusion: the understanding and utterance of the word meaning depends on context. Vocabulary teaching must be combined with context which particular words occur. It is very important for students to acquire the context information. Only with this can they catch word meaning, and strengthen the ability to 
use vocabulary freely. Teachers should always take the context in vocabulary teaching into consideration.

It is also an efficient way for them to master the meanings of new words and choose appropriate words to express themselves in writing or communication.

With the limited space, not enough materials, preliminary research and other factors, the paper is only a tentative study of the application of context. And the classification and analysis of word proceeded will probably not present a complete pattern. More examples and words will be put out in the further research.

\section{REFERENCES}

[1] Da Weidong, (1998). General Theory of Modern Linguistics in English. Shanghai: Shanghai Foreign Language Education Press.

[2] Halliday, M. A. K. and A. M. Peter. (1964). The Linguistic Sciences and Language Teaching. London: Longman.

[3] Halliday, M. A. K. (1978). Language as Social Semiotic. London: Edward Arnold.

[4] Halliday, M. A. K. and R. Hasan. (1976). Cohesion in English. London: Longman.

[5] Halliday, M. A. K. \& R. Hasan. (1985). Language, Context and Text. Oxford: Oxford University Press.

[6] Halliday, M. A. K. and R. Hasan. (1989). Language, Context, and Text: Aspects of Language in a Social-semiotic Perspective. Oxford: Cambridge University Press.

[7] He Zhaoxiong, (1989). General Pragmatics. Shanghai: Shanghai Foreign Education Press.

[8] Hu Zhuanglin, (2002). Diverse Study of Context. Foreign Language Teaching and Research, 2002, 3.78-81.

[9] Lyons, J. (1977). Semantics. Cambridge: Cambridge University Press.

[10] Leech, G. (1981). Semantics: The Study of Meaning. England: Penguin Books Ltd.

[11] Rivers, W. M. (1968). Teaching Foreign-Language Skills. Chicago: University of Chicago.

[12] Robinett, B. W. (1980). Teaching English to Speaker of Other Languages. Minnesota: Minnesota University Press.

[13] Zhang Yunfei. (1988). General Theory of Modern English Vocabulary. Beijing: Beijing Normal University Press.

Xiaohui Xu was born in Zibo, China in 1977. She received her M.A. degree in Foreign Linguistics and Applied Linguistics from Ocean University of China in 2010.

She is currently a lecturer in the School of Foreign Languages, Qingdao University of Science and Technology, Qingdao, China. Her research interests include Second Language Acquisition and English teaching. 